\title{
The effect of social-cultural factors on foreign students' well being: Evidence from Thailand universities
}

Dao Duy Tung

Graduate school of Management, Siam University, Bangkok 10160, Thailand

Corresponding author: howie@tungdao.net

\begin{abstract}
The aim of this study was the primary focus of the international students remains on the academic adjustment aspect, which stays as the cornerstone of their well-being and satisfaction. The questionnaire data collected from four universities, both public and private, were analyzed to provide proof. The results from methods analyzing data stated that there was a positive impact of social-cultural factors affecting well-being. And this research finds no significant evidence of the difference in levels of adaptation between male and female students. The finding also implies that the university and the authority should focus on the positives of the issue, possibly needs some more attention to derive benefits from this potent sector.
\end{abstract}

Keywords: mental health, Hofstede, higher education sector, student's well-being, Thailand.

\section{$1 \quad$ Introduction}

Adaptation challenges of international students is an important issue which is relevant to the globalization of higher education over the last few decades. Prospective international students seeking opportunities abroad is an ongoing trend that causes a large number of student inflow in many countries that provide the high quality in education (Lieb, 2016). Bochner (2006) described international students as 'student sojourners' who travel abroad for a limited tenure in order to attain a pre-determined educational goal. According to Lieb (2016), between the year 2000 and 2011, the number of international students increased by 75 percent globally, taking the figure to 3.7 million tallies (Organisation for Economic Co-operation \& Development, 2013), which may reach to about 7.2 million by the year 2026 (Smith, 2012). 
Recently, some Asian countries are chosen by potential international students for the reasons of economy, convenience and diverse experiential knowledge (Mustaffa \& Ilias, 2013). Most of the relevant studies available focused on the adaptation challenges of international students of North American universities and other developed countries. But studies related to international students in Asian countries have not been correspondingly adequate. Organisation for Economic Co-operation \& Development (2013) report, Japan, Malaysia and South Korea are the top three destinations in Asia for international students, and Thailand is still far behind. On the other hand, the researchers have identified numerous adjustment issues related to international students. While residing in a foreign country, the international students are often exposed to unfamiliar and challenging socio-cultural and academic environments (Araujo, 2011). Student achievements were affected due to lack of linguistic ability (English), standard of education background, learning skills, socio-cultural adjustment issues and demographic factors (Smith, 2012). In Thailand, many international students also encounter multi-faceted adaptation challenges and they adopt coping strategies as regards academic and non-academic difficulties (Rujipak \& Limprasert, 2016). The university authorities can play an important role by taking positive institutional approach. Studies on international students in Thailand have been notably limited in number and perspective. Smith (2012) surveyed Chinese students studying Thai-language at Mahasarakham university and found cultural and academic adjustment problems. Rujipak and Limprasert (2016) studied the well-being and socio-cultural adaptability of mostly undergraduate students in Mahidol university and suggested a lower degree of adjustment by Asian students, compared to Western students. International students' satisfaction was found related to the perceived image of the university (Ngamkamollert \& Ruangkanjanases, 2015). However, the relationship between socio-cultural adjustment and adjustment of the international students need to be further studied as it will positively influence future aspirants to choose Thailand for future destination of higher study. 
This study examined the extent to which the international students are being able to make sociocultural adjustments and how does it relate to their well-being while they study an international program at a public or private university in Thailand. The possible relationship between the degree of socio-cultural adjustment by the international students and its resultant effect on their well-being was the focus of this limited study. Therefore, this is the basic interest of carrying out this research by the researcher, who is also an international student in Thailand.

\section{Background and hypotheses}

\subsection{Academic adjustment and well-being}

It is the adjustment to the specific academic study including styles of teaching and learning by the international students. International students' difficulties in adapting to overseas study programs are primarily influenced by academic stressors, language ability, variation in pedagogy, confidence level and sociability of students (Rujipak \& Limprasert, 2016). The academic adjustment ( $A C D A D J)$ of the international students is influenced by 'culture shock' and the individual is subjected to a wide-ranging experience in a new cultural orientation. According to McInerney and King (2015), little is known about the academic motivation of the sojourners as they relocate from home to host cultural arena. It can cause stress for the international students. This difficulty, however, may be reduced based on the availability of positive social support. Rujipak and Limprasert (2016) showed in their study that ACDADJ has a significant positive relationship with the students' wellbeing. It is predicted that, $A C D A D J$ challenges may have positive association with the level of well-being of the students. In view of the above the following hypothesis is proposed.

H1: The academic adjustment level positively associated with well-being

\subsection{Physical health and well-being}

It is the state of physical, mental and emotional health of the international student and their transformation in the host country. These transformations can cause acculturative stress leading to mental agony and affecting mental and physical health $(M H)$. Referring to Schumann's 
acculturation model theory, (Berry, 2015) suggests four core acculturation strategies employed by groups and individuals in a foreign cross-cultural environment, namely, Assimilation (leave inherited traditions and absorb into the new culture); Integration (remain connected to both home and host culture); Separation (retaining own heritages and disinterested to acquire host culture); Marginalization (fully disconnected and isolated). According to Berry (2015), these can cause affect $M H$, create aloofness, emotional distress, and crisis about self-identity. It is therefore, predicted that, the state of physical and mental health of international students will maintain a positive association with the individual's well-being.

H2: The maintain of physical and mental health positively associated with well-being.

\subsection{Interpersonal relationship and well-being}

It is the adaptation to the local and international peers in personal dimension and with teachers and staff in the academic dimension. When studying abroad, the international students are expected to display decreased anxiety and increased willingness to interact with native speakers, as well as greater oral proficiency and cultural understanding (Rujipak \& Limprasert, 2016). According to Mustaffa and Ilias (2013), there is a positive link between developing interpersonal relationship (IP) involving personal emotional factor, and cross-cultural adjustment. Finally, greater socio-cultural adjustment and less stress were found among international students who interacted with students from the host culture. Students who were in the integration and assimilation modes displayed lower levels of acculturative stress level compared to those who were in the separation and marginalization modes (Lieb, 2016). It is hence predicted that the higher $I P$ shall positively contribute to the higher well-being.

H3: The interpersonal relationship level positively associated with well-being.

\subsection{Local culture and well-being}

It is the adjustment to the host culture involving student's confidence in performing social and daily tasks individually in the new country (Lee \& Pistole, 2014). Ward and Kennedy (1999) underpinned that adjustment to local culture $(L C)$ is very important for sojourners. According 
to Baba and Hosoda (2014), the perceived discrimination, societal disconnectedness, and culture shock are most noticeable among sojourners who represent high cultural distance from the host country. Compared to American society that promotes independence and self-reliance, the Asian students face high degree of acculturative stress as they hail from collectivist societies that values interdependence and close bondedness (Baba \& Hosoda, 2014). According to Ward and Kennedy (1999), communication skill is positively related to sociocultural adjustment. Behavioral alterations consist of learning local languages, cuisine, attire, and societal exchanges in conformity with the new culture (Berry, 2015). Social-support networks, particularly involving local co-students, play a key role in the socio-cultural adjustment of international students (Baba \& Hosoda, 2014) and reduce levels of acculturative stress ultimately leading to wellness. Thus, the following hypothesis is proposed.

H4: The international students get accustomed to the local culture positively associated with their well-being.

\subsection{Living condition and well-being}

Defined as the acclimatization with the place of residence and its neighborhood by the international student. Living within campus or within foreign societal environment, and cohabiting with culturally similar or distant person may also make adaptation differences. Living away from home, friends and folks is often challenging, and it affects the well-being of an international student. While at temporary residence, many other everyday challenges come up which can be summarized as financial need, transportation need, quality of living quarters and condition of living environment (Smith, 2012). As Zhou, Jindal-Snape, Topping, and Todman (2008) suggested, a helpful neighborhood and a supportive landlady can make difference in the well-being and the adjustment process.

H5: The satisfied the place of residence and neighborhood positively associated with well-being. 


\section{Research method}

\subsection{Sample and data instrument}

The method pursued during the research was quantitative design and questioning sample population that represent the research topic so that the results may be extrapolated to entire population under study. For the current study, the researcher considered both private and public universities as the data source. Target population for this study was all the international students undertaking study programs in private and public universities in Thailand. International students studying in Bangkok was considered as the sample frame. Four universities were then chosen randomly, as the planned sample. These are, Siam university in Phasi-Charoen district, Assumption university in Bang Na district and NIDA in Bangkapi district, University Ubonratchathani Rajabhat in Ubon Ratchathani Province. The current study was conducted by collecting data through a field survey using a structured questionnaire as the survey instrument. This kind of questionnaire reduces bias as researcher's opinions will not influence respondents' answers and is easy to analyze using software. Necessary verbal approval was obtained from the university authorities prior to the survey. Data was collected following non-probability snowball sampling method. It was a combination of circulation of the web-version questionnaire to known international students who recirculated to their peers, and also using pen and paper survey by physical distribution of the questionnaire to the international students.

\subsection{Variable measurements}

The five concepts of socio-cultural adjustment were measured using the scale developed by Uehara (1988) which was also used by Rujipak and Limprasert (2016), in his study on Mahidol university international students. The same instrument was used with minor adjustments in the language of some items. The 39-item instrument contains the questionnaire. Items were measured using a five-point Likert scale which varied from "Strongly Disagree" $=1$ to "Strongly Agree" =5. The well-being data was collected using "Satisfaction with Life 
Scale' (SWLS) that was developed by Diener, Emmons, Larsen, and Griffin (1985). It was measured using a five-item instrument operationalize the level of well-being and satisfaction with life. Items were measured using a seven-point Likert scale which was also used by Rujipak and Limprasert (2016) with values varying from "Strongly Disagree" = 1 to "Strongly Agree" $=7$. Mean score was obtained from all the variables item-wise using software. The mean scores were used to measure and compare between variables, and control variables were primarily the demographic and personal information.

\subsection{Control variables}

The control variables in the research encompassed demographic factors of international student included, age, gender, marital status, education level, years in the university.

\subsection{Data analysis}

After the responses to the survey questionnaires were received, the researcher used statistical methods to analyze the data using a combination of SPSS primarily. Mean comparison was carried out by conducting independent samples t-test and ANOVA between demographic variables and comparison of the socio-cultural adjustment factors and well-being. Correlation between the concepts were found out by Pearson's bivariate correlation analysis. Stepwise regression analysis was also carried out to examine relationships between each concept and inference based on the model and the proposed hypotheses.

\section{Result}

\subsection{Demographic respondents}

The study was 82 from four universities in Bangkok. NIDA had 26 (31.7\%), Siam had 33 (40.2\%), ABBAC had 9 (11\%), UBR had 14 (17.1\%) respondents (as seen table 1).

Table 1. Statistics demographic of respondents

\begin{tabular}{l|lll}
\multirow{2}{*}{ Demographic } & \multicolumn{3}{l}{ Descriptive statistics } \\
\cline { 2 - 4 } & & Frequency & Percentage \\
\hline Gender & Male & 35 & 42.7 \\
& Female & 47 & 57.3 \\
\hline
\end{tabular}




\begin{tabular}{llll}
\hline Nationality & Non-Asia & 9 & 11.0 \\
& Asia & 73 & 89.0 \\
\hline Living environment & Alone & 50 & 61.0 \\
& Foreign & 24 & 29.3 \\
& Thai & 8 & 9.80 \\
\hline Education level & Undergraduate & 22 & 26.8 \\
& Master & 41 & 50.0 \\
& Doctoral & 19 & 23.2 \\
\hline Name of university & NIDA & 26 & 31.7 \\
& Siam & 33 & 40.2 \\
& ABBAC & 9 & 11.0 \\
& UBR & 14 & 17.1 \\
\hline
\end{tabular}

\subsection{Descriptive analysis}

The results revealed that the international students have reported to have inclined towards academic adjustment in all five factors of socio-cultural adjustment, with higher mean $(\mathrm{M}=$ 3.7500, $\mathrm{SD}=0.50875)$. In opposite, local culture has lowest mean $(\mathrm{M}=3.5874, \mathrm{SD}=0.62043)$ and experiencing high psychological well-being during their study in Thailand universities

Table 2. Mean and St. Deviation of summated scales

\begin{tabular}{|l|l|l|l|l|l|l|}
\hline & ACDADJ & MH & IR & LC & LCON & WB \\
\hline Mean & 3.7500 & 3.5976 & 3.7154 & 3.5874 & 3.7271 & 4.7220 \\
\hline SD & 0.50875 & 0.61917 & 0.59287 & 0.62043 & .51300 & 0.95930 \\
\hline
\end{tabular}

\subsection{Reliability and Validity of the constructs}

Table 3 shows that Cronbach's alpha score of local culture $(\alpha=0.780), \operatorname{LCON}(\alpha=0.792)$ and WB $(\alpha=0.755)$ are within acceptable range but the scores of MH, ACDADJ and IP were found to be poor $(\alpha<0.6)$. In order to test the validity of the concepts, exploratory factory analysis was carried out with KMO and Bartlett's test for sampling adequacy.

Table 3. Reliability test result

\begin{tabular}{|l|c|c|c|l|}
\hline Variables & observed variables & alpha & loading & Remark \\
\hline ACDADJ & 10 & 0.820 & 0.788 & Removed 1 item \\
\hline
\end{tabular}




\begin{tabular}{|l|c|c|c|l|}
\hline MH & 4 & 0.586 & 0.605 & Removed 3 items \\
\hline IR & 6 & 0.727 & 0.736 & Removed 1 item \\
\hline LC & 6 & 0.780 & 0.803 & \\
\hline LCON & 8 & 0.792 & 0.756 & \\
\hline WB & 5 & 0.755 & 0.749 & \\
\hline
\end{tabular}

\subsection{Testing mean values}

Table 4 shows that there is no significant difference based on gender in achieving socio-cultural adjustment, though the female students have slightly higher level of adjustment in all five factors. For WB, it showed almost same level of adjustment for both male and female. However, these results are not statistically significant $(\mathrm{p}>0.05)$ in all factors. As regards nationality, Asian and non-Asian respondents, the Asians showed higher degree of satisfaction with LCON which is statistically significant $(p<0.05)$. Except in adjustment to local culture, the Asian students have reported higher levels of ACDADJ, MH, and IP and showing higher level of well-being than the non-Asian students, but these results are not statistically significant ( $p>0.05$ ). Living with a Thai or a foreigner results in slightly higher level of well-being compared to staying alone but there is no remarkable difference in levels of socio-cultural adjustment. However, these results are not statistically significant $(\mathrm{p}>0.05)$.

Table 4. Comparisons adjustment levels with factors

\begin{tabular}{|c|c|c|c|c|c|c|c|c|c|c|c|c|}
\hline \multicolumn{13}{|c|}{ Gender } \\
\hline & \multicolumn{2}{|c|}{ ACDADJ } & \multicolumn{2}{|c|}{$\mathrm{MH}$} & \multicolumn{2}{|c|}{ IR } & \multicolumn{2}{|c|}{$\mathrm{LC}$} & \multicolumn{2}{|c|}{ LCON } & \multicolumn{2}{|c|}{ WB } \\
\hline & $\mathrm{M}$ & SD & $\mathrm{M}$ & SD & $\mathrm{M}$ & SD & $\mathrm{M}$ & SD & $\mathrm{M}$ & SD & $\mathrm{M}$ & SD \\
\hline $\begin{array}{c}\text { Male } \\
(n=47)\end{array}$ & 3.66 & 0.56 & 3.52 & 0.65 & 3.68 & 0.63 & 3.55 & 0.68 & 3.68 & 0.58 & 4.78 & 1.01 \\
\hline \multirow[t]{3}{*}{$\begin{array}{l}\text { Female } \\
(n=35)\end{array}$} & 3.88 & 0.41 & 3.66 & 0.51 & 3.76 & 0.54 & 3.63 & 0.54 & 3.79 & 0.41 & 4.64 & 0.89 \\
\hline & \multirow{2}{*}{\multicolumn{2}{|c|}{$\begin{array}{l}\mathrm{t}=1.988 \\
\mathrm{p}=0.052\end{array}$}} & \multirow{2}{*}{\multicolumn{2}{|c|}{$\begin{array}{l}\mathrm{t}=1.061 \\
\mathrm{p}=0.292\end{array}$}} & \multirow{2}{*}{\multicolumn{2}{|c|}{$\begin{array}{l}\mathrm{t}=0.610 \\
\mathrm{p}=0.544\end{array}$}} & \multirow{2}{*}{\multicolumn{2}{|c|}{$\begin{array}{l}\mathrm{t}=0.576 \\
\mathrm{p}=0.566\end{array}$}} & \multirow{2}{*}{\multicolumn{2}{|c|}{$\begin{array}{l}\mathrm{t}=0.891 \\
\mathrm{p}=0.375\end{array}$}} & \multirow{2}{*}{\multicolumn{2}{|c|}{$\begin{array}{l}\mathrm{t}=-0.665 \\
\mathrm{p}=0.508\end{array}$}} \\
\hline & & & & & & & & & & & & \\
\hline & & & & & Nat & lity & & & & & & \\
\hline
\end{tabular}




\begin{tabular}{|c|c|c|c|c|c|c|c|c|c|c|c|c|}
\hline $\begin{array}{c}\text { Asian } \\
(\mathrm{n}=73)\end{array}$ & 3.78 & 0.51 & 3.59 & 0.57 & 3.73 & 0.59 & 3.59 & 0.60 & 3.79 & 0.44 & 4.70 & 0.95 \\
\hline $\begin{array}{c}\text { Non-Asia } \\
(\mathrm{n}=9)\end{array}$ & 3.53 & 0.47 & 3.44 & 0.81 & 3.63 & 0.64 & 3.56 & 0.82 & 3.24 & 0.79 & 4.91 & 1.07 \\
\hline & $\begin{array}{c}\mathrm{F}=1.853 \\
\mathrm{p}=0.177\end{array}$ & $\begin{array}{c}\mathrm{F}=0.615 \\
\mathrm{p}=0.435\end{array}$ & $\begin{array}{c}\mathrm{F}=0.210 \\
\mathrm{p}=0.648\end{array}$ & $\begin{array}{c}\mathrm{F}=0.026 \\
\mathrm{p}=0.872\end{array}$ & $\begin{array}{c}\mathrm{F}=10.329 \\
\mathrm{p}=0.002\end{array}$ & $\begin{array}{c}\mathrm{F}=0.390 \\
\mathrm{p}=0.534\end{array}$ \\
\hline
\end{tabular}

Living alone versus Living with others

\begin{tabular}{|c|c|c|c|c|c|c|c|c|c|c|c|c|}
\hline $\begin{array}{c}\text { Alone } \\
(\mathrm{n}=50)\end{array}$ & 3.77 & 0.56 & 3.56 & 0.63 & 3.68 & 0.65 & 3.62 & 0.67 & 3.74 & 0.56 & 4.66 & 0.96 \\
\hline $\begin{array}{l}\text { Others } \\
(\mathrm{n}=32)\end{array}$ & 3.72 & 0.43 & 3.60 & 0.55 & 3.77 & 0.49 & 3.54 & 0.54 & 3.71 & 0.44 & 4.82 & 0.96 \\
\cline { 1 - 9 } & $\mathrm{F}=0.196$ & $\mathrm{~F}=0.194$ & $\mathrm{~F}=0.373$ & $\mathrm{~F}=0.351$ & $\mathrm{~F}=0.052$ \\
$\mathrm{p}=0.659$ & $\mathrm{p}=0.661$ & $\mathrm{p}=0.543$ & $\mathrm{p}=0.555$ & $\mathrm{p}=0.821$ & $\mathrm{p}=0.468$ \\
\hline
\end{tabular}

\subsection{The integration between social-cultural factors and well-being}

Table 5 shows results indicate that international students who had attained higher academic performances, developed greater IP, adjusted better with the local culture and satisfied with LCON and maintained moderate MH have had greater levels of well-being than those students who adjusted poorly in levels of socio-cultural factors. The result showed that all five factors are positively correlated with well-being. Except $\mathrm{MH}(\mathrm{p}>0.05)$, other factors are statistically significantly strongly and positively associated with well-being.

Table 5. The correlation between social-cultural factors and well-being

\begin{tabular}{|l|l|r|r|r|r|r|r|}
\cline { 2 - 8 } \multicolumn{2}{c|}{} & ACDADJ & MH & IR & LC & LCON & WB \\
\hline \multirow{2}{*}{ ACDADJ } & Pearson & 1 & & & & & \\
\cline { 2 - 9 } & Sig. (2-tailed) & & & & & & \\
\hline \multirow{2}{*}{ MH } & Pearson & 0.207 & 1 & & & & \\
\cline { 2 - 9 } & Sig. (2-tailed) & 0.062 & & & & & \\
\hline LC & Pearson & $0.527^{* *}$ & 0.123 & 1 & & & \\
\cline { 2 - 9 } & Sig. (2-tailed) & 0.000 & 0.270 & & & & \\
\hline LCON & Pearson & $0.287^{* *}$ & 0.015 & $0.446^{* *}$ & & & \\
\cline { 2 - 9 } & Sig. (2-tailed) & 0.009 & 0.893 & 0.000 & & & \\
\hline
\end{tabular}




\begin{tabular}{|l|l|r|r|r|r|r|r|}
\hline & Sig. (2-tailed) & 0.001 & 0.382 & 0.000 & 0.000 & & \\
\hline WB & Pearson & $0.363 * *$ & 0.068 & $0.364 * *$ & $0.337 * *$ & $0.309^{* *}$ & 1 \\
\cline { 2 - 8 } & Sig. (2-tailed) & 0.001 & 0.546 & 0.001 & 0.002 & 0.005 & \\
\hline
\end{tabular}

**. Correlation is significant at the 0.01 level (2-tailed).

\subsection{Hypotheses verification}

Linear regression was done step by step keeping adjustment as the dependent variable and adding socio-cultural concepts one by one.

Table 6. Result of linear regression to establish relationship between concepts

\begin{tabular}{|l|r|l|l|l|r|}
\hline & ACDADJ & MH & IR & LC & LCON \\
\hline $\mathrm{R}^{2}$ & 0.132 & 0.032 & 0.133 & 0.113 & 0.095 \\
\hline$\beta$ & 0.363 & 0.179 & 0.364 & 0.337 & 0.309 \\
\hline t-value & 3.487 & 1.630 & 3.498 & 3.197 & 2.902 \\
\hline Sig & 0.001 & 0.107 & 0.001 & 0.002 & 0.005 \\
\hline
\end{tabular}

Given the statistical methods outlines above, the five hypotheses meet the criteria for statistically significant as describe. Hypothesis 1 positively associated between international student well-being and ACDADJ at university $(\beta=0.363, p<0.05)$. Hence, hypothesis 1 is supported. Hypothesis 2 positively associated link between international student well-being and $\mathrm{MH}$ at university $(\beta=0.032, \mathrm{p}>0.05)$. Hence, hypothesis 2 is supported. Hypothesis 3 positively associated between international student well-being and IP at university $(\beta=0.364$, $\mathrm{p}<0.05)$. Hence, hypothesis 3 is supported. Hypothesis 4 positively associated between international student well-being and LC at university $(\beta=0.337, \mathrm{p}<0.05)$. Hence, hypothesis 4 is supported. Hypothesis 5 positively associated between international student well-being and LCON at university $(\beta=0.095, \mathrm{p}<0.05)$. Hence, hypothesis 5 is supported. 


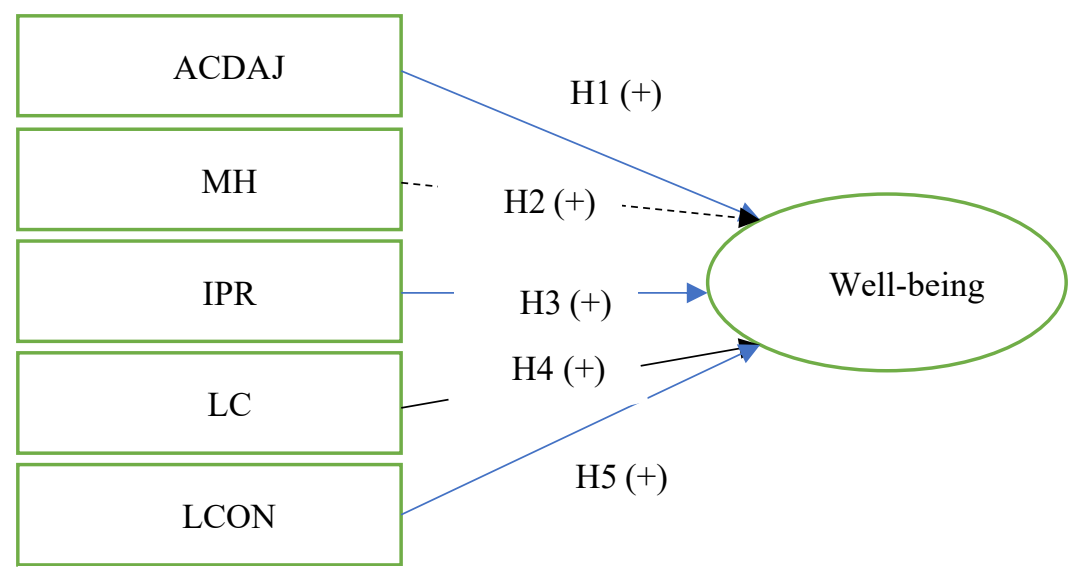

Figure 1. The result hypothesis testing

\section{Discussion and Conclusion}

\subsection{Key findings}

This study attempted to examine the possible relationship between the various factors contributing to the socio-cultural adjustment and well-being of the international students while they attempt to attain their respective educational goals. The international students often reside in a foreign country for a limited period of time, particularly in the Asian countries. They seek an interim solution or makeshift arrangement in terms of adaptation strategy while trying to materialize their educational goals. Acculturation challenges of foreign students in the western countries are different from those faced by international students who come to study in Asian universities. In Thailand, the medium of international education is English, but the people mostly speak the local Thai language. This difference, however, has not been found as an additional challenge of acculturation during the current study. In spite of the explanations of Hofstede's cultural dimension theory, the Thai culture and its friendly people remain welcoming to millions of foreign visitors every year. The people extend meaningfully positive assistance that makes Thailand a lucrative destination of tourism. Conversely, the internationalization of education sector has not seen an equivalent growth compared to some other Asian countries.

The findings of the study indicate a sound adaptation by most of the international students coming to study in Thailand irrespective of their nationality or socio-cultural 
orientation. This denotes that the international students who come to another country for higher study are motivated, willing and somewhat ready to go the extra mile to get acquainted with the norms, practices and uniqueness of the host culture, society and the new academic environment. This finding is similar to Rujipak and Limprasert (2016) where they studied undergraduate students and found age group in excess of 25 years were more likely to adapt. The respondents of current study were from 16 different countries hence it was not prudent to assess their level of adaptability country-wise. Rather, comparing the results of Asian and nonAsian students, the Asian students showed higher likelihood to adapt but this finding is not statistically supported. It however is contrary to that of Rujipak and Limprasert (2016) where westerners showed better adaptability than Asian students at Mahidol university. The students staying alone or with a foreigner or Thai friend did not show any significant difference in adaptation. Duration of stay in Thailand and length of study at the university also have significantly different results. Marital status and previous travel experience were also analyzed and did reveal any significant difference in adaptation process of the students.

The research was found from the analysis of the results that socio-cultural adjustment levels of the international students contribute significantly in raising the level of their wellbeing and promote better quality of life. Individually all five factors socio-cultural adjustment, namely, ACDADJ, MH, IP, LC and LCON were positively associated with WB of the international students. Except for $\mathrm{MH}$ factor, all the other factors also showed statistically significant relationship. But when all the factors were put together in regression analysis, the result was not so significantly positive. Only IR showed significant positive relationship while all other factors showed insignificant results. This finding is not fully consistent with the previous study by Rujipak and Limprasert (2016). One possible reason could be that the previous study considered a monocular approach taking sample from a single reputed public university; whereas the current study focused on diverse subjects from a combination of public 
and private universities of mixed standard and repute. Given a larger sample size, the findings of this study could be more solidified.

\subsection{Limitations}

In this study, the sample size is a limitation. The research should increase the sample size in the future, to make the sample more representative.

\subsection{Conclusion}

The study was seen that without developing Thai language skills, the students are already successfully adjusting to the host culture and it is also positively improving their health. This ultimately shall contribute in furthering their educational goals in Thailand. The current study is a relevant topic that demands due consideration to see a positive outcome in the internationalization of higher education sector of Thailand. It is hoped that the findings of this research shall be contributory to the better understanding of the various challenges that the international students may be experiencing while they come to Thailand to meet their educational aspirations and goals. The universities shall also benefit from this activity by gaining cross-cultural experiences which may be useful in many other future opportunities.

\section{References}

Araujo, A. A. d. (2011). Adjustment issues of international students enrolled in American colleges and universities: A review of the literature. Higher Education Studies, 1(1), 2-8. https://doi.org/10.5539/hes.v1n1p2

Baba, Y., \& Hosoda, M. (2014). Home away home: Better understanding of the role of social support in predicting cross-cultural adjustment among international students. College Student Journal, 48(1), 1-15.

Berry, J. W. (2015). Acculturation: Living successfully in two cultures. International Journal of Intercultural Relations, 29, 697-712.

Bochner, S. (2006). Sojourners. In D. L. Sam \& J. W. Berry (Eds.), The Cambridge handbook of acculturation psychology (pp. 181-197). Cambridge, New York: Cambridge University Press. 
Diener, E., Emmons, R. A., Larsen, R. J., \& Griffin, S. (1985). The Satisfaction With Life Scale. Journal of Personality Assessment, 49(1), 71-75. https://doi.org/10.1207/s15327752jpa4901_13

Lee, j.-y., \& Pistole, M. C. (2014). International student sociocultural adaptation: Gossip and place attachment. Journal of Mental Health Counseling, 36(4), 345-359.

Lieb, M. M. (2016). Meeting the needs of international students. Journal of Alternative Perspectives in the Social Sciences, 7(3), 400-422.

McInerney, D. M., \& King, R. B. (2015). Studying “a thousand miles away": The motivational implications of cross-cultural transitions. Transactions Across Schools and Cultures, 17, 205-240. https://doi.org/10.1108/S0749-7423(2012)0000017011

Mustaffa, C. S., \& Ilias, M. (2013). Relationship between students' adjustment factors and cross-cultural adjustment: A survey at the Northern university of Malaysia. Intercultural Communication Studies, 22(1), 279-300.

Ngamkamollert, T., \& Ruangkanjanases, A. (2015). Factors influencing foreign students' satisfaction toward international program in Thai universities. International Journal of Information and Education Technology, 5(3), 170-178. https://doi.org/10.7763/IJIET.2015.V5.497

Organisation for Economic Co-operation \& Development (2013). How is International Student Mobility Shaping Up? Education Indicators in Focus, 1-4.

Rujipak, V., \& Limprasert, S. (2016). International students' adjustment in Thailand. $A B A C$ Journal, 36(1), 34-46.

Uehara, M. (1988). International students' cross-cultural adaptation. Hiroshima: Takahashi Press.

Ward, C., \& Kennedy, A. (1999). The measurement of sociocultural adaptation. International

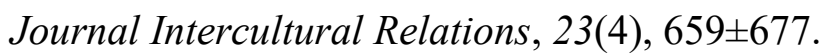

Zhou, Y., Jindal-Snape, D., Topping, K., \& Todman, J. (2008). Theoretical models of culture shock and adaptation in international students in higher education. Studies in Higher Education, 33(1), 63-75. https://doi.org/10.1080/03075070701794833 